\title{
EVE'S DISSOCIATIVE IDENTITY DISORDER AS THE REFLECTION OF HER UNPLEASANT CHILDHOOD IN NUNALLY JOHNSON MOVIE, THE THREE FACES OF EVE
}

\author{
Priyoto \\ Sekolah Tinggi bahasa Asing (STBA) Pertiwi Indonesia \\ Email: pri_ck4@yahoo.co.id \\ Lia Aulia \\ Sekolah Tinggi bahasa Asing (STBA) Pertiwi Indonesia \\ Email:lia_aulia@gmail.com
}

APA Citation: Priyoto \& Aulia, L. (2019). Eve's Dissociative Identity Disorder As The Reflection Of Her Unpleasant Childhood In Nunally Johnson Movie, The Three Faces Of Eve. Journal of English Language and literature, 4(2), 28-38. DOI 10.37110/jell.v4i02.77

Received: 20-07-2019

Accepted: 05-08-2019

Published:01-09-2019

\begin{abstract}
The objectives of this study are: (1) to explain the causes of Eve's dissociative identity disorder. Eve has three identities in her body; Eve White, Eve Black and Jane; (2) to compare the personalities of each identity; and (3) to discuss more deeply the effect of Eve's dissociative identity disorder to her psychological condition and her ways in facing dissociative identity disorder. This movie tells about dissociative identity disorder as the effect of unpleasant childhood. The personalities of each identity: Eve White, Eve Black and Jane are very different. They battle to be the master of its body. In analyzing this movie, the writer uses psychological approach because the problems of the movie relate to psychological issue like dissociative identity disorder. The method of research the writer used is qualitative. That means the method of this thesis deliver words rather than numbers as the data to be analyzed. The data in this thesis was collected by home-library. The writer reads books, journals, articles, and some offline books in collecting the data resources.
\end{abstract}

Key words: dissociative identity disorder, psychological condition, psychological issue

\section{INTRODUCTION}

The Three Faces of Eve was first released by Cinema Scope on 12 September 1957. This movie needed no help from the imagination of a fiction writer. The truth itself was fabulous enough and much of the dialogues taken from the clinical record of Corbett $\mathrm{H}$. Thigpen and Hervey M. Cleckly because they were psychiatrists who handled Chris Costner Sizemore as Eve in a real life who suffered from Dissociative Identity Disorder. Their account of the case was delivered to the American Psychiatric Association in 1953 and it was already a classic of psychiatric literature.

The Three Face of Eve is a story about a woman who suffers from Dissociative Identity Disorder. Eve has three identities inside her body: Eve White, Eve Black and Jane. Each identity has different behaviors, gestures, and memories. Eve White depicts as a woman who has husband, Ralph and daughter, Bonnie in the first scene of this film. She is demure, quiet, and even-tempered, while, Eve Black admits as a single woman who does not have husband and daughter. She enjoys going to pub every night, dating with men, drinking alcohol and even smoking. Then, Jane is the only identity who is very stable in facing every problem. She behaves very sweet to Bonnie as if she is her mother, while, she differs from Eve Black who has ever choked Bonnie.

The aim of this study is the first is to know deeply the causes of Eve's Dissociative Identity Disorder. The second is to compare Eve's personalities from each alter after suffering from Dissociative Identity Disorder. The third is to find out the effects of Eve's Dissociative Identity Disorder. 


\section{REVIEW OF LITERATURE}

The writer provides more details the theories that she uses to answer the formulated problems that relate to the movie The Three Faces of Eve. As the writer's consideration, she begins with Trauma theory to provide the starting point why the main character has dissociative identity disorder. Then, she applies Dissociative Identity Disorder, Model of Personality by Costa and McCrae, Anxiety and Depression, Psychoanalysis and Self-defense Mechanisms by Sigmund Freud.

\section{Trauma}

Everyone, either children or adult, can experience trauma. Trauma comes from traumatic events that appear fear and anxiety, while people cannot cope with. A traumatic event is any situation that people subjectively experience as distressing or frightening. These events can be something experienced only by the individual (e.g. being in an accident, witnessing a terrible event) or can be events in which groups of people were involved such as floods, storms and bushfires. (2011:4)

Some people experience a traumatic event during their childhood. Unfortunately, some children experience a number of traumas and the effects may be cumulative and making children more vulnerable to stress reaction. Children may present with similar pattern of trauma symptoms, the way children process and respond to a traumatic event depends on their age and development maturity. (2011:9)

\section{Trauma Response: Dissociation}

After getting terrible event that disturb people's emotion, dissociation becomes a trauma response that people can do. Dissociation is defined as a disruption in the usually integrated functions of unconsciousness, memory, identity, or perception of the environment. People can also split off memories from consciousness awareness, and develop to amnesia. They can develop amnesia for their entire identity and begin a separate life. (Bloom, 1999:7)

In this part, the explanation below can bring to the term dissociative identity disorder in which has relationship to trauma. The DID reaction is characterized by detaching (forgetting) part of one's experience, usually a very stressful series of events, from the center of one's awareness. Often the traumatic childhood experience involves sadistic bizzare or sexual mistreatment by a parent or principal caretaker. The dissociation of the experience serves an obvious purpose: it blocks out painful and shaming experiences, memories, or states of mind. If you are overwhelmed by bad experience, avoiding it or repressing it or detaching from it is one way to escape. In this situation your mentally create another reality. (Tucker, 2004:23)

It implies that trauma really relates to DID (Dissociative Identity Disorder) as people's response towards terrible. Dissociative Identity Disorder becomes people's way to escape from traumatic event that they experience in childhood. This way has purpose to wipe out painful and shaming experiences, memories, or states of mind.

\section{Kinds of Traumatic Event}

In analyzing trauma case, the writer describes kinds of traumatic event based on The Post Traumatic Stress Disorder by Glenn R. Schiraldi, Ph.D. (2009:5):

a. Intentional Human

There are a lot of examples of intentional human, they are as follows:

(1) rape; forced nudity, exhibitionism, or pornography; inappropriate touching, fondling and kissing; (2) physical; beating, slapping, kicking, battering, choking, stalking, forcing to eat or drink, elder abuse by own children; (3) emotional; intimidation, degrading names, economic neglect, minimizing or denying abuse; (4) snipper attack; (5) witnessing home suicide; (6) kidnapping; and (g) death threat. b. Unintentional Human

These examples are classified as unintentional human because it occurs because of accidents or technological disasters; (1) Industrial; crane crashes down; (2) fire, burns; an oilrig catches fire; and (3) Explosion.

c. Natural Disaster

As we know, natural disaster occurs without people who get involved. It can be seen as acts of nature; (1) Hurricane; (2) Typhoon; (3) Flood; (4) earthquake, (5) volcanic eruption, and (6) sudden death; loss of unborn childhood.

\section{Dissociative Identity Disorder}




\section{Definition of Dissociative Identity Disorder (DID)}

Diagnostic and Statistical Manual of Mental Disorders V (2013:292) provides the definition of Dissociative Identity Disorder "The defining feature of dissociative identity disorder is the presence of two or more distinct personality states or an experience of possession". It implies a person who has different

A person with DID experiences himself or herself as having separate identities, known as alters. There are some other terms for alters such as alternate identity, distinct identity, personality, personality state, part of the mind and part of the self. Therefore, each alter can take over control of the person's body or behavior at various time. (Alters in Dissociative Identity Disorder, 2017)

\section{Symptoms}

Every illness or disorder has symptoms. Its function is to recognize what kind of illness or disorder that people suffer from. For example, a doctor diagnoses his patient that she/he suffers from Anemia after checking that the patient has a low hemoglobin, insomnia, and dizziness. In psychology, every disorder such as mental or personality disorder has symptoms. Hence, the writer explores the symptoms of Dissociative Identity Disorder by Diagnostic and Statistical Manual of Mental Disorders V(DSM-V).

a. Having Two or More Distinct Identities

Absolutely, People with Dissociative Identity Disorder have two or more personalities inside the body. Each personality has own behaviors, perceptions, gestures, memory, and cognition (2013:292). There are three type of personality, the first is host personality, the main personality that escapes to protect from its trauma. The second is persecutor personality, giving pain or punishment to other personalities such as jumping in front of a truck and then, going back inside the body, leaving other personalities to experience the pain. The third is protector/helper personality, this personality takes a role as an adviser to the host personality or behaves something that the host personality is inability to do. (2011:169)

\section{b. Periods of Amnesia}

Typically, People who suffer from this disorder state that they have periods of amnesia.
They do not remember what they have done or why suddenly they lay in the bed even before they have a dinner in a restaurant. Susan and Hoeksema support it in their book Abnormal Psychology that "They describe being completely amnesic for the periods when other personalities are in control or having one-way amnesia between certain personalities." (2011:170)

From the statement above, one alter can be totally amnesic when the other personalities take control the body.

c. Terrible Headache

This terrible headache attacks unexpectedly when another personality wants to come out. Commonly, a terrible headache can be the first sign from other symptoms when another personality will take control the body.

d. Mood Swings

Actually, everybody has mood swings. They come as a natural part of most people who are alive. They are happy and then they are sad. John M. Grohol (2016) gives the definition of mood swings in his article All About Mood Swings that "A mood swing is simply a noticeable change in one's mood or emotional state". However, in many cases, mood swings are one of symptoms of more serious health issues because some people's mood swings are extreme and serious. For example, they roar with laughter, at the second later, they feel sad. Thus, People who suffer from Dissociative Identity Disorder experience mood swings because of the changing of alter. When the alter changes, its mood automatically changes.

\section{Model of Personality}

Model of Personality is known as The Big Five or Five-Factor Model (FFM) which proclaimed by Costa and McCrae in early 1990s. Essentially, this theory is used to measure basic personality traits. It differs from low and high in each factor.

\section{Neuroticism}

Neuroticism refers to the degree of emotional stability. How people accept unpleasant event, people with high neuroticism tend to be anger, anxiety, depression, or vulnerability. Meanwhile, people have a low neuroticism are quiet, reserved, sober, passive and unfeeling.

\section{Extraversion}


Extraversion is related to emotional. People who are classified as extraversion tend to be talkative, easygoing, active and passionate. Mostly, people with extraversion have a good emotional stability. Amirkhan gives his conclusion in his research about extraverts "A study of 100 men and women college students found that those high in extraversion were able to cope with everyday life stress." (qtd. in Sydney and Duane, 2009:285)

\section{Openness}

Typically, people seek a new experience towards something. For instance, people try to make a new recipe. People with high on openness tend to question traditional values, meanwhile, people with low on openness preserves traditional values. They are creative, imaginative, liberal and curious people.

\section{Agreeableness}

In this trait, agreeableness distinguishes people who are good-natured from irritable ones. They are softhearted, trusting, generous, acquiescent, lenient good-natured. Then, people who are low agreeableness tend to Ruthless, suspicious, stingy, antagonistic, critical, and irritable.

\section{Conscientiousness}

The last model, conscientiousness means people who tend to controlled, organized, and ordered. Generally, people who have high score on conscientiousness are hardworking, conscientious, and punctual. In contrast, people who have low score tend to be lazy, negligent, and late.

\section{Psychological Effects of Dissociative Identity Disorder}

\section{Anxiety}

All of people, young or adult, male or female has been confronted with conditions that arouse the emotion of fear and anxiety from time to time. Whether the cause is fear of walking alone in the darkness, or anxiety of being an employee at the new office. Definitely, fear and anxiety are different. Thus, the writer provides the difference between fear and anxiety from Carissa Kelvins, in her article Fear and Anxiety, that:

There is an overall basic distinction between fear and anxiety. Anxiety is a vague pleasant emotional state with qualities of apprehension, dread, distress, and uneasiness. In addition, it is objectless. Fear is similar to anxiety except that fear has a specific object. (1997)

Simply, anxiety and fear differs from an object. On the other hand, Anxiety is when people worries towards something that has not happened yet. Meanwhile, fear is feeling afraid of definite object. For instance, they are fear of loss weight, fear of snack or fear of staying in the darkness. Fear and anxiety that experienced in a long-term can lead people to suffer from anxiety disorder.

There are the symptoms of anxiety disorder. They are as follows:

(1) Emotional symptoms such as feeling of apprehension or dread, feeling tense and jumpy, restlessness or irritability, anticipating the worst and being watchful for signs of danger; and (2) physical symptoms are like pounding and racing heart and shortness of breath, upset stomach, sweating, tremors and twitches, headache, fatigue, insomnia and frequent urination diarrhea. (National Alliance on Mental Illness, n.d)

\section{Depression}

People have time when their mood is low, and they will feel sad, gloomy and miserable about life. If the feelings are interfering with their life and do not go away after a couple of weeks, or if they do not get well, it could be a sign that they experience depression. Rashmi Nemade and Natalie Staats (2007) in their article Cognitive Theories of Major Depression explain the tendency of depressed people about life, that, "Depressed people tend view themselves, their environment and the future in a negative and pessimistic light". Therefore, people who are depression go through their life with negativity side, and pessimistic. It seems they have no eagerness to continue their life. It affects the way a person thinks, feels and behaves.

To facilitate the readers, the writer provides the symptoms of depression by Katherine Dunn, in her article Understanding Depression:

Common signs and symptoms of depression; (a) down, upset and fearful; (b) restless, agitated, or irritable; (c) 
guilty, worthless and down on yourself; (d) empty and numb; (e) finding no pleasure in life or things you usually enjoy; (f) a sense of unreality; (g) no selfconfidence or self-esteem; (h) hopeless and despairing; and (i) suicidal. (2016:4)

Depression has three levels to measure how depressed people are. It is supported by Depression article (n.d):

1. Mild, it is undiagnosed because the symptoms are not considered to be "bad enough" for people to think they may have depression. It requires at least two of the five symptoms. Over a period of more than 2 weeks, and cause disruption of the person's normal activities.

2. Moderate, it requires five or six of the ten symptoms. Having negative beliefs such as loss of self-esteem and inappropriate guilt are the core symptoms of depression

3. Severe, it can be called major depression. People experience with seven or more of the ten symptoms, delusions, hallucinations, or depressive stupor. Typically, they are consistent with themes of depression involving death, disease, or some sense of deserved punishment.

The more depressed they are the harder symptoms they have. Mild, moderate and severe are significant level of depression that depend on the intensity of symptoms present.

\section{Psychoanalysis}

Freud argues that the mind has three categories. There are the id, ego and superego. From each category has connection to another category. This theory helps people to understand how the mind develops and works.

1. The Id

The id is the most primitive part of the mind that relates to unconsciousness. It is only about anything what people want to because the id serves the pleasure principle. Sydney and Duane give more explanation about the id that "The aspect of personality allied with the instincts; the source of psychic energy, the id operates according to the pleasure principle" (2009:57). For instance, there is a boy who steals a new car in showroom even though he should kill people who tries to caught him. It can happen because the id has no morality. It is only due to fulfil one purpose, seeking pleasure.

\section{The Ego}

The ego is the only part of the mind in which contact with reality. It grows out of the id and becomes a person's sole source of communication with the external world. The Ego tries to substitute for the pleasure principle of the id becomes reality principle. In the other words, the ego becomes the decision-making of personality. Freud as quoted in Jess and Gregory describes:

The ego becomes differentiated from the id when infants learn to distinguish themselves from the outer world. While the id remains unchanged, the ego continues to develop strategies for handling the id's unrealistic and unrelenting demands for pleasure" (2006:29).

It means The Ego can be a mediator between a pleasure and a reality. The Ego will decide and consider what the merits and demerits of something.

\section{Superego}

In Freudian psychology, Superego represents moral and ideal aspects of personality. It is guided by the moralistic and idealistic principles as opposed to the pleasure principle of the id and the realistic principle of the ego. The system of Superego according to Jess and Gregory is described as follows:

The superego has two subsystems, the conscience and the ego-ideal. Freud did not clearly distinguish between these two functions, but, in general, the conscience results from experiences with punishments for improper behavior and tells us what we should not do, whereas the ego-ideal develops from experiences with rewards for proper behavior and tells us what we should do (2006:36).

It means conscience can be described as guilt feeling when people do wrong and ego-ideal as a pride feeling when people get rewards.

\section{Self-Defense Mechanisms}

Freud elaborated on the idea of defense mechanisms in 1926 and his daughter Anna further refined and organized the concept. 
Sydney and Duane (2009:61) give the definition of self-defense mechanisms that "Strategies the ego uses to defend itself against the anxiety provoked by conflicts of everyday life. Defence mechanisms involve denials or distortions of reality". It states that self-defense mechanisms are people's ways to protect themselves in facing conflicts every day.

According to Freud, there are eight selfdefense mechanisms. In this occasion, the writer discusses all of them obviously.

\section{Repression}

Repression is a way of forgetting something that brings discomfort or pain feeling. Hence, people will do this defense unconsciously. Hence, people do not feel that they have any unpleasant event. Freud in Sydney and Duane's book Theories of Personality (2009:62) argues "The concept of repression is the basis of much of Freud's personality theory and is involved in all neurotic behavior". It means repression is commonly used by people in their life.

2. Denial

Denial relates to repression and involves denying the existence of some external threats or traumatic events that has occurred. For example, Parents of a child who has died may continue to deny the loss by keeping the child's room unchanged.

\section{Reaction Formation}

One defense against a disturbing impulse is to express the opposite impulse. Mostly, people who do not like something tend to avoid, but in this way, they do what they hate oppositely even they do exaggeratedly. This is called reaction formation. For instance, a man who is jealous to his brother, on the contrary, he behaves as if he loves his brother so much.

\section{Projection}

Projection is a defense mechanism where an impulse that causes anxiety delivers to someone else. For example, Andre loves Susan. When his friend asks him, he answers, "I don't love her. She loves me." Andre does not want to seem that he loves Susan.

\section{Regression}

In regression, a person retreats an earlier period of life that is more pleasant and free of anxiety. Regression usually involves a return to one of the psychosexual stages of childhood development such as a thumb sucking. It is only to satisfy their sexual not their nutritional needs.

\section{Rationalization}

Rationalization is a way that involves reinterpreting our behaviors to make them seem more rational and acceptable to us. For instance, a person who does not pass the interview test in flight company may rationalize by saying the job is not good one for her.

7. Displacement

If an object that satisfies an id impulse is not available, the person may reallocate the impulse to another object. This is known as displacement. For example, a drummer player who is angry to his instructor punches the drum repeatedly. He does not hit his instructor because of some reasons such as avoiding punishment. It is a way to satisfy an id impulse. 8. Sublimation

Displacement involves finding a substitute object to satisfy id impulses. People try to change their primitive pleasure by behaving acceptable. For instance, a man who wants to satisfy his sexuality substitutes by painting the naked people.

\section{METHOD}

This research is qualitative research. It named design of qualitative research. Design of qualitative research divided into four; (a) grounded theory (b) ethnography; (c) case study; and (d) content analysis. From those designs, the writer only applies content analysis in her thesis. Cole as quoted in Satu and Helvi defines that "Content analysis is a method of analyzing written, verbal or visual messages." (2008)

\section{FINDING AND DISCUSSION}

The Causes of Eve's Dissociative Identity Disorder and her Personalities

\section{Trauma: Coercion To Kiss A Dead face}

Eve has trauma in her childhood when she was six years old. She only knows something that she likes and dislikes such as playing with her friends, showing her interests, speaking up what she feels, and refusing what she does notwant to directly. Moreover, Eve still has unstable emotion, thus, she cannot be forced to do something that she does not like.

Eve gets emotional distress after kissing her grandmother. This reason seems so normal because children can experience a condition when their parents give an order to do something such as eating vegetables, stop 
playing games and watching a movie that actually, they do not like. However, every child has different emotional stability. Therefore, this event becomes a traumatic event for Eve. It is supported by Hoeksema in his book Abnormal Psychology (2011:169) that "Childhood trauma is often associated with the development of dissociative identity disorder." To escape from her terrible memory after kissing a dead face, she splits her identity into Eve White as the victim of the trauma in childhood, in order to reduce her pain and forget her trauma.

\section{Loss of Her Baby}

Loss of loved ones means we no longer have what we really want to. Commonly, losing of loved ones makes people feel very sad, depressed and can ruin their quality of life. In this case, Eve White described as a mother who gets an abort to her second child.

From Eve's White confessions to Dr. Luther, "I lost another baby about four months ago". Her expression changes from flat become a gloomy one. The changing of facial expression infers that loss of her baby is a terrible event and she cannot face it. Implicitly, as an alter that made as the victim of traumatic event, loss of her baby becomes the second tragedy that worsens her Dissociative Identity Disorder.

\section{A Temperamental Husband}

Ralph White is described as a temperamental husband after her wife behaves unpredictably. $\mathrm{He}$ is easy to angry and using her temper to face Eve's behavior. Moreover, when Eve Black does not do his command like Eve White used to. He often says in terrible words and slaps her wife.

Ralph is mad when he knows from Miss Effie Blanford (e.g. Miss Effie Blandford is a woman who works in a store that Eve buys new clothes and shoes) that her wife has bought new clothes and shoes without his permission. Because of this thing, Ralph feels that his pride as a husband falls out. Ralph shows his angry by saying, "I got a good mind to slap your face" his words make Eve White frightened. Ralph points out that he is a temperamental husband.

\section{The Comparison of Eve's Personalities}

Obviously, Eve who suffers from Dissociative Identity Disorder has different personalities. In this occasion, the writer compares the personalities among Eve White, Eve Black and Jane to know the difference personalities of each identity.

\section{Eve White's Personalities}

a. Demure

Demure means woman's behavior that is reserved, modest and shy. From scene by scene, Eve White always behaves well to other people, especially, Dr. Luther, a psychiatrist whom she often meets, not only her-about behavior but also her appearance in the way she dressesing. Eve White points out that her appearance represents her personality.

In a normal condition, speakings softly is a usual thing, but Eve White till prefers lookings down to lookings at her interlocutor, Dr Luther. It is her way to avoid eye contact in speaking. Meanwhile, she always wears proper clothes. When she feels uncomfortable with clothes, she holds the collar to cover her neck. By showing the way she speaksing and dressesing proofs that she is the demure ones. After analyzing Eve White's behavior, she points out that she has low extraversion.

b. Quiet

Eve White is described as a woman with low extraversion. She faces her problems with calmness, no anger, and no complainant. Eve White shows her quietness when she should live separately with her family, in order to prevent unexpected consequences because other alters have possibility to do harm to other people.

In this scene, Eve White seems that she accepts Dr. Luther's advice very well. If people were Eve White, they would have got angry towards their conditions, thrown things to release their emotion, blamed anyone towards this disorder, but it does not happen to Eve White. She is very calm in facing her Dissociative Identity Disorder.

\section{c. Even-Tempered}

Even-tempered relates to neuroticism or people's emotion. Eve White who is eventempered tends to be calm in every situation and not easily irritated towards something.

Eve White works as a call acceptor. She seems to be fine, doing her job properly. She shows that she can keep her emotion until she asks to a caller to wait twice; it can be seen from her statement "Hold for just a minute. Hold just 
a moment". Until a terrible headache attacks, and her identity changes to Eve Black. A terrible headache that experienced by Eve White is one of the symptoms of Dissociative Identity Disorder and becomes the first sign of the changing of personality. From the conversation, Eve White points out that she has low neuroticism because she is calm when she faces a caller who is in a hurry.

\section{d. Trusting}

Trusting can be described as showing or tending to have a belief in a person's honesty or sincerity, not suspicious to others. In this case, Eve White has a strong believe towards Dr. Luther, as the person whom she depends on and understand all of her feelings.

\section{Eve Black's Personalities}

a. Mischievous

Eve Black is very different with Eve White. She is the second alter, which comes out inside the body. She displayed as a woman who is an attractive one and she often behaves impudently. She makes her life differ from Eve White, she does anything that is impossible for Eve White.

Eve Black is a fun loving woman, usually, she is so cheerful and does anything what she wants to like going to pub, dancing on the stage, dating with men, drinking alcohol and even smoking. She hass high extraversion because she feels comfortable in the middle of crowd and is easy to express her strong emotion. Her aim is only one, making her life full of joy.

b. Temperamental

Eve Black who is extraverted personality tends to be temperamental one, she would rather release her anger or dislike than conceal from others. Even though, she is the second identity, it does not make her become the calm one.

Eve Black behaves, as she wants to without thinking about the consequences of her behavior towards Eve White's image in her office, like her answering to a caller "I don't care who you are. Blast off, Buster." Eve Black is so temperament by saying bad words to a caller. Therefore, Eve Black has high neuroticism.

c. Ruthless

Being a ruthless one is described of Eve Black as having or showing no pity or compassion for others. Eve Black tends to ignore someone else who needs her help or even she can do harm when she feels disturbed. The writer proves Eve Black's personality from this narration and conversation:

Having high neuroticism makes Eve Black cannot control her emotion and leads her to do harm thing to others. Eve Black never feels that Bonnies is her child, she is going to be irritable one after someone disturbs her. Therefore, she chooses to hurt Bonnie, in order to make Bonnie stops whining.

From this proof, the writer assumes that Eve Black is a low agreeableness because she cannot accept Bonnie as her daughter.

d. Irresponsibility

Eve Black's behaviors that have explained much more above show that she has no responsibility as a woman, she only knows how to satisfy her desires, nothing else. Besides, Eve Black also points out her irresponsibility in her relationship with men. She dates with different men, but there is no sign that she is serious through the relationship.

\section{e. Suspicious}

Jane's emergence makes Eve Black feels uncomfortable. Previously, there are only her and Eve White. She does not assume Dr. Luther is going to like Eve White because Eve White depicts as a weak person. Then, Eve Black knows that Jane has a pleasant personality. She starts to think that Dr. Luther would rather like Jane than her.

Eve Black really knows that Jane is a very good woman. She is fit for anything as a woman: she successes to make Bonnie feels comfortable, has a man who loves her even though she has dissociative identity disorder and behaves very well to other people. She thinks that Dr. Luther will like Jane. From Eve Black's low intonation in the end of questioning, "Do you like her?" is full of suspicion. Still, she asks to convince that Dr. Luther likes her "More than you do me."

\section{Jane's Personalities}

a. Stable

Jane is the last identity that appears after escaping from her trauma in childhood for a long time. She is the only one who is stable. She can control herself even more she does not show any complicated problem because of her Dissociative Identity Disorder like Eve White 
who should live separately from her family and Eve Black who only takes care of herself.

From this narration, Jane shows her relationship with Earl, a man who loves her unconditionally and the writer analyzes that there is no betrayal in their relationship until the end of the movie.

\section{b. Softhearted}

Jane who is very kind and compassionate to others is categorized as softhearted one. Then, Jane shows her softhearted to Bonnie. She behaves to Bonnie very well and returns her respect and comfortable feeling to her mother after Eve Black chokes her.

The writer infers that there are the three biggest problems in Eve's life that make her suffer from Dissociative Identity Disorder; (1) trauma in her childhood, (2) loss of her baby, (3) and his temperamental husband. Unconsciously, Eve in childhood creates new alter, as known Eve White to take a role of victim in the trauma. Meanwhile, losing of baby and having temperamental husband make Eve White's emotion and psyche are more terrible, then, leads her to have additional alter, and she is Eve Black. Then, Jane (the real Eve in childhood) is the host identity, escapes into the protection of psychological oblivion and has no memory at all even her name. Therefore, she suffers from Dissociative Identity Disorder.

After analyzing the personalities of the three identities: Eve White, Eve Black and Jane, the writer infers that Eve White is a woman who is demure, quiet, low-tempered and trusting. Having these personalities, makes Eve White depicted as a weak woman. Then, Eve Black is a mischievous, fun-loving, ruthless, temperamental, irresponsibility and suspicious. It shows that she has strong personality in negative side. The last, Jane is softhearted and stable. Even though, Jane has no scene as much as Eve White and Eve Black, Jane's personalities is fit for everything. She behaves sweet to Bonnie as if she is Bonnie's mother, she is loyal to Earl and she faces every problem with her emotional stability.

\section{Eve's Psychological effects After Suffering from Dissociative Identity Disorder and her ways in facing Dissociative Identity Disorder}

\section{Eve's Psychological Condition}

Having Dissociative Identity Disorder is not easy to through life. Even though, Dissociative Identity Disorder is the impact of people's strategy in coping intolerable trauma or terrible events, apparently, it also affects to Eve's psychological condition such as anxiety, and depression.

\section{Anxiety}

Anxiety comes from over thinking towards life in the future and it happens to Eve White. She becomes the one who always worries when enduring Dissociative Identity Disorder.

Eve White worries about her disorder that can give impact to her marriage life. However, she is not a person who can handle serious problems by herself. She starts worrying her Dissociative Identity Disorder, she presumes that she cannot heal and meet her daughter.

Her anxiety towards Bonnie is getting hard. Actually, it can be a normal feeling because a mother has strong feelings to her child, but in this part, her anxiety becomes excessive. It can be seen from her statement "I wanted to jump out of that truck and go hug her."

It does not stop about her worry that cannot meet Bonnie, it continues to herself. After knowing about other alters from Dr. Luther, Eve Black is irresponsible, Jane is stable and she is the only one who is gloomy every time makes her more agitated.

Eve White declares her statements with short breath in which indicates the symptom of anxiety. Eve White has been through her life with low-spirited and low self-esteem. There is no reason for her to fight, because Bonnie and Ralph have left her. Nevertheless, her personalities are not suitable to be the only identity that will stay: she is demure, quiet, and even-tempered. She cannot handle everything. Then, she knows how Jane behaves. She assumes that Jane is fit for everything-she can be a good wife and mother either. Eve White also realizes that only a strong personality, which will stay in this body and she knows Jane will stay and win this battle to be the master of the body. This fact makes her full of hopeless.

Eve Black's psychological condition is also disturbed like Eve White. She proves it by showing her negativity and hopelessness. She 
cries even she never does before. It proves Eve Black has psychological condition disturbance.

\section{Depression}

Dissociative identity disorder destroys Eve White's efforts to make her marriage life full of joy. For Eve White, making husband happy is one of goals of being a wife, a wife who will serve her husband sincerely. Eve White loves Ralph, she has tried anything to make her husband pleased, taking care Bonnie, washing clothes, cooking meals and complying with his order, but she thinks it is not good enough. Ralph never looks at her efforts. He always infuriates towards her behavior, why she buys expensive new clothes without his permission, goes to savannah and does not come home, dances in the nightclub, although, all of those things have been done by Eve Black. This situation makes Eve White's psychological condition disturbed.

A psychological condition becomes a reason why the changing of identity occurs. The worse psychological condition, the easier other identity comes out.

\section{Suicide Attempt}

Experiencing anxiety and depression are associated to suicide attempt. It is supported by Hara Estroff Marano, in her article Anxiety and Depression Together describes the risk of undergoing anxiety and depression together, that:

The coexistence of anxiety and depression called comorbidity in the psych bizz-carries some serious repercussions. It makes the course of disorder more chronic, it impairs functioning at work and in relationship more, and it substantially raises suicide risk. $(2003: 1)$

In this case, it has explained that Eve White experiences anxiety and depression together. Therefore, she has high risk to do suicide attempt. Moreover, Eve White's marriage has life ruined. Ralph, a man whom she loves has left her, while Bonnie feels frightened towards her and lives with her grandmother. Eve White's life has dedicated to Ralph, and she has given all of her love to Bonnie. So that, when they are gone, her life is meaningless.
Eve Black is the only witness when Eve White does suicide attempt, she confesses it to Dr. Luther. By doing suicide attempt, Eve White points out that she cannot face her problems come to her life since she has Dissociative Identity Disorder. It is supported by Diagnostic and Statistical Manual of Mental Disorders explains, that:

Over $70 \%$ of patients with dissociative identity disorder have attempted suicide; multiple attempts are common, and other self-injurious behavior is frequent. Assessment of suicide risk may be complicated when there is amnesia for past suicidal behavior or when the presenting identity does not feel suicidal and is unaware that other dissociated identities do.

(2013:295)

The explanation above proves that over 70\% patients with DID do suicide attempt. Furthermore, she thinks that suicide is the easiest way to end the problems such as dissociative identity disorder and loneliness. By doing suicide, other identities will die either. Thus, there is no more Eve Black and Jane. In this case, she points out that her depression in severe level, the worst level of depression. Even though, she does not show any experience like hallucination and delusion as the symptom of depression in severe level, by doing suicide attempt has proved that she is very depressed.

\section{A. CONCLUSIONS}

The triggering factor of Eve's dissociative identity disorder is coercion to kiss a dead face from her parents, then leads her to get trauma. Dissociative Identity Disorder becomes her way to cope with her trauma, she splits her identity to Eve White. Loss of her baby and a temperamental husband worsen her dissociative identity disorder that make Eve Black emerges. Having dissociative identity disorder, obviously, influences to psychological condition from each identity such as anxiety, depression and suicide risk.

In facing Dissociative Identity Disorder, Eve does some self-defense mechanisms such as denial, projection, reaction formation and repression in order to protect herself from conflicts. Then, she goes to psychiatrists and does some treatments such as psychotherapy and hypnosis to cure her disorder. 


\section{BIBLIOGRAPHY}

Alters in Dissociative Identity Disorder. 2017. Retrieved on March 13, 2017, from http://traumadissociation.com/alters

American Psychiatric Association. (2013). Diagnostic and Statistical Manual of Mental Disorders. $5^{\text {th }}$ Ed. Arlington: APA

Bloom, Sandra L. 1999. Trauma Theory Abbreviated. Philadelphia:

Community Works

Cambridge Advanced Learner's Dictionary. 2013. India: Replika Press Pvt. Ltd

Dunn, Katherine. 2016. Understanding Depression. London:Mind

Elo, Satu and Helvi Kyangas. 2008. The Qualitative Content Analysis Process. Finland: Blackwell Publishing Ltd

Feist, Jess and Gregory J. Feist. .Theories of Personality. New York: The McGraw-Hill Companies

Hudson. 1939. An Introduction To The Study of Literature. London: George G. Harap \& Company

H. M, Abrams. 1999. A Glossary of Literary Terms. USA: Earl McPeek

Kelvens, Carissa. 1997. Fear and Anxiety. Retrieved on May 18, 2017, from www.csun.edu/ ucppsy00h/students/ fear.htm

Kenardy, Justin, et al. 2011. Children Trauma Reactions. Australia: Conrod

Lloyd, Craig. 2005. Nunally Johnson 18971977. Retrieved on July 17, 2017, from http://www.georgiaencyclopedia.org/ articles/arts-culture/nunnallyjohnson-1897-1977

Nemade, Rashmi. 2007. Cognitive Theories of Major Depression. Retrieved on May 15, 2017, from www.mentalhelp.net/articles/cogniti ve-theories-of-major-depressionaaron-beck/

Marano, Hana Estroff. 2003. Anxiety and Depression Together. Retrieved on May 18, 2017, from www.psychologytoday.com/articles/ 200310/amxiety-and-depressiontogether

Murphy, Gardner. 2012. Pengantar Psikologi Umum. Jakarta: Rajawali Pers

Oxford Online Dictionary. Retrieved November 8, 2016, from https://en.oxforddictionaries.com

Psychological Dictionary. Retrieved November 8, 2016, from http://psychologydictionary.org/neur otic-trend/

Rossman, Gretchen B and Sharon F. Rallis. 2012. Learning in the Field: An Introduction to Qualitative Research. USA: Sage Publications, Inc.

Schiraldi, Glenn R. 2009. The Post Traumatic Stress Disorder. New York: McGraw Hill

Schultz, Duane and Sydney Ellen, ed. 2009. Theories of Personality. USA: Wadsworth. 